\title{
M odernidade e crise semântica: obstáculos epistemológicos à formação da prova no direito ambiental
}

\author{
Guilherme de Azevedo ${ }^{1}$ \\ Luís Fernando Moraes de Mello ${ }^{2}$
}

\begin{abstract}
Resumo
A tradição processual, sustentada pelo projeto cientificista moderno, encontra dificuldades em compor os problemas ambientais de forma idônea à sua complexidade constitutiva. Este trabalho tem por objetivo a análise da crise semântica social e dos seus reflexos na operatividade da prova no direito ambiental. Ao racionalismo epistemológico pode ser atribuído a inspiração das características metodológicas da ciência moderna, como controlabilidade, causalidade, determinismo e axiomatização. Esta concepção de ciência irá sedimentar as bases da teoria jurídica moderna, sendo, portanto, imprescindível sua descrição para compreendermos a estrutura da teoria probatória no Direito, e sua (in)capacidade de abarcar as demandas da sociedade complexa, como por exemplo, os litígios ambientais.
\end{abstract}

Palavras-chave: Modernidade; Prova; Direito Ambiental.

\section{Introdução}

A necessidade de uma explicação universalista da realidade, a partir do Renascimento, levou a tradição racionalista - Descartes, Malenbranche, Spinoza, Leibniz, Wolff - ao ápice do seu desenvolvimento. Neste período, erigiu-se a Razão ao status de fundamento último do conhecimento, ou seja, a Razão se torna o princípio possibilitador do conhecimento universal da realidade.

Contudo, a relação entre Razão e Modernidade não está identificada numa única orientação filosófica, como, por exemplo, o racionalismo de inspiração cartesiana. Durante o período moderno, a Razão estava presente no desenvolvimento de duas orientações filosóficas: o racionalismo e o empirismo.

\footnotetext{
${ }^{1}$ Mestrando em Direito pela Universidade do Vale do Rio dos Sinos - Unisinos. Bolsista CAPES - Brasil. E-mail: egg.azevedo@gmail.com

${ }^{2}$ Mestrando em Direito pela Universidade do Vale do Rio dos Sinos - Unisinos. Bolsista CNPq - Brasil. E-mail: luisfernandomello@yahoo.com.br
}

Revista de Direito Púbuco, LondRina, V, 4, N. 3, P. 195-209, SEt./ DeZ. 2009. 
Para o racionalismo, o conhecimento completo, verdadeiro, tem origem no uso da Razão. Nesta corrente de pensamento, a Razão assume um caráter gnosiológico e epistemológico, isto é, posiciona-se como fonte originária do conhecer. Principal expoente deste pensamento, e para muitos, tido como o "pai da filosofia moderna", Descartes representou um novo nível na tradição, ao laicizar o seu sistema filosófico. 0 método cartesiano é um ícone do paradigma racionalista ao partir da premissa que só se pode admitir como verdadeiro aquilo que se apresenta de forma evidente ao espírito (FERRARTER MORA, 1971, p. 517-519). Em outras palavras, a verdade é constituída de evidências originárias, simples, irredutíveis, ou de noções relacionadas com elas. Tal postura epistemológica levou a reflexão cartesiana a um processo de dúvida metódica, que passou da desvalorização da influência empírica à formação do juízo "penso, logo existo", tido como única base irrefutável de qualquer atividade cognitiva.

Por outro lado, merece igual destaque a influência do empirismo na construção do pensamento moderno, que, em contraponto ao racionalismo, funda o conhecimento na experiência. Para os empiristas, o sujeito cognoscente é como uma "tabula rasa", no sentido lockeano, onde se inscrevem as impressões originárias do mundo externo. Os dados recebidos do mundo exterior pelo sujeito cognoscente são chamados idéias ou sensações (FERRARTER MORA, 1971, p. 513-517). Estas idéias ou sensações são a base do conhecimento para corrente empírica, sem, contudo, dispensar totalmente a Razão.

O que diferencia o racionalismo do empirismo é a forma como a Razão é tratada em suas respectivas filosofias. Na primeira, a Razão possui um caráter absoluto, isto é, ela atinge o status de pedra angular do conhecimento, fundando toda atividade cognoscitiva. Já na tradição empirista, como anteriormente demonstramos, o uso da Razão não é preponderante na formação de sua epistemologia.

Embora tenha ocorrido o paralelismo das duas orientações filosóficas no período moderno, o racionalismo tornou-se dominante na tradição continental. A modernidade é marcada pela unidade e absolutização da Razão. Este domínio da Razão implica a centralização do sujeito no modo de conhecer e estabelecer relações de sentido com 0 mundo.

0 processo de racionalização do mundo é possibilitado pela construção da subjetividade. Assim, na modernidade, o sujeito é pensado a partir da sua relação 
objetificante com o mundo, sendo compreendido como um sujeito cognoscente, que está para um objeto a ser conhecido, em virtude de uma co-relação sujeito-objeto. A relação sujeito/objeto tem suas origens no pensamento grego, passando pelo medievo e chegando a modernidade. Entretanto, a forma de se pensar essa relação na antiguidade e no medievo é distinta do período moderno. Tanto na antiguidade com no medievo, a figura do sujeito esta localizada numa visão de adequação à ordem cosmológica, isto é, ele está em uma relação de conformidade com as coisas. Na modernidade há uma virada antropocêntrica, onde 0 mundo não é mais pensado a partir do cosmos, e sim de um paradigma da consciência. É por esse motivo que a Razão é elevada ao status de princípio explicativo do mundo, com pretensão universalista. A partir deste esquema, o sujeito passa a conhecer o objeto pelo uso da Razão.

A autoridade da Razão implica na construção de uma metodologia que conduza o pensar a conclusões exatas, verificáveis e demonstráveis, com validade e vigência universais, independente das condições históricas do sujeito conhecedor do objeto e das circunstâncias do próprio objeto. Com este objetivo, o racionalismo desenvolveu um pensar sustentado pelo cálculo, privilegiando a lógica matemática como modelo para a construção de uma metodologia para a ciência.

A idealização de uma objetividade na construção do sentido, para as ciências do espírito, levou a equiparação do seu método ao rigor matemático da metodologia das ciências naturais (DILTHEY, 1948). A utilização do paradigma matemático exige da construção das ciências do espírito uma lógica formal ajustada aos mesmos critérios de verificabilidade, demonstrabilidade, axiomatização, com uma finalidade específica: a controlabilidade do conhecimento.

A busca pela objetividade determina que todo ato cognoscitivo esteja fundado em um método que conduza o sujeito ao conhecimento da verdade das coisas. 0 controle sobre a relação cognoscitiva entre sujeito e objeto é a principal forma de se evitar que os pressupostos históricos e ideológicos do sujeito interfiram no conhecimento. Logo, o método representa este projeto moderno de controle do conhecimento.

Com isso, a modernidade se caracteriza por uma tentativa de solidificar 0 conhecimento, adotando parâmetros e regras aptos a fornecer uma segurança epistemológica na estruturação de suas ciências. 


\section{0 legado moderno da técnica}

Uma das principais transformações geradas pelo paradigma racionalista da modernidade pode ser observada no desenvolvimento da técnica. É na modernidade que se inicia um processo de transformações que mudaram as características da técnica, alterando significativamente as possibilidades de intervenção na natureza pela ação humana.

0 primeiro fator determinante destas transformações foi a confluência do conhecimento científico com a técnica. Até o princípio da modernidade, o saber (ciência) e o fazer (técnica) se desenvolviam separadamente. 0 papel desempenhado pela ciência era a busca da compreensão e explicação teórica dos fenômenos, enquanto a função da técnica era o controle destes fenômenos. Na tradição da antigüidade, a ciência deveria apontar o conhecimento rigoroso e demonstrativo. À atitude prática cabia o bem-fazer de um agente qualquer. E à atitude poética concernia a criação de uma coisa distinta de seu criador. A ciência tinha um caráter contemplativo. Esta atitude contemplativa possuía um predomínio em relação à atitude prática e produtiva. Neste quadro, a racionalidade técnica era assinalada por um status inferior. A implicação determinante da fusão entre ciência e técnica é o fato de que, pela primeira vez, penetrou-se teoricamente o domínio prático da natureza (HÜBNER, 1979, p. 462).

No início da ciência moderna, nos séculos XV ao XVII, modificou-se o projeto ocidental de ciência, direcionando-o para a operatividade (tecnomatemática), como indica Hottois:

[...] en la historia de Occidente, el proyecto de la ciencia o del saber se ha confundido con el proyecto teórico. Etimológicamente, el término "teoría" evoca la visión, la contemplación. Pero la teoría presenta también la forma de un logos, de un discurso racional. El proyecto teórico es, pues, un discurso racional articulado que contempla o refleja la estructura racional de lo real. El saber es "logoteoría". Este proyecto perteneció, primeramente, a la filosofía (con la que la ciencia se confundió durante mucho tiempo). Pasó a ser, posteriormente, el de la ciencia Ilamada pura. (HOTTOIS, 1999. p. 13) 


\section{Modernidade e crise semântica: obstáculos epistemológicos à formação da prova do direito}

ambiental

Assim, a ciência deixa de estar estruturada por uma linguagem natural, passando a ser constituída por uma lógica matemática e mecanicista, baseada na experimentação (experiência provocada e ativa que isola fenômenos e se serve de instrumentos).

Com a ciência antiga, o homem fazia a mediação com o mundo pela linguagem. A antiga ciência filosófica era uma semântica (ordem conceitual) que organizava as significações dadas pela linguagem. 0 objetivo deste modelo de ciência é construir um corpo logicamente organizado a partir de definições (que enunciam a essência dos seres e das coisas) e princípios. Com este trabalho, a semântica da linguagem natural seria organizada e estabilizada. Este modelo de ciência não permite que se promova uma intervenção efetiva no real (HOTTOIS , 1999, p.15).

Já a ciência moderna, caracteriza-se pela matematização e experimentação. Estas características nos fazem romper com o "ser-natural-no-mundo-pela-linguagem". Com isto, o mundo é privado de significação. Ele passa a ser um campo de operação e de ação. Portanto, se no paradigma da ciência antiga a mediação entre homem e mundo era feita por meio da linguagem, na ciência moderna caberá à técnica o papel de fazer esta mediação.

No modo de pensar inaugurado pela ciência moderna, não há ciência sem técnica. Todo conhecimento científico pressupõe a utilização de instrumentos de medição e máquinas quantificadoras. A finalidade do conhecimento é o controle, havendo a coincidência entre ciência e poder. Esta concepção de ciência e este modo do ser humano se relacionar com a natureza inspiraram to do o desenvolvimento da modernidade.

Procurando traçar uma distinção entre técnica pré-moderna e moderna, Hans Jonas diz que a tecnologia moderna é um empreendimento e não uma posse, um processo e não um estado, um impulso dinâmico e não uma provisão de ferramentas e habilidades. $A$ natureza era compreendida como um objeto que deveria ser submetido ao domínio humano. A partir da revolução científica do século XVII, este domínio passaria a estar teorizado pela ciência moderna.

Como aponta Vicente de Paulo Barretto, o primeiro grande resultado desta confluência consistiu na transformação das forças naturais em forças de trabalho artificiais, como foi o caso paradigmático da invenção da máquina a vapor. Dessa forma,

[...] o sistema produtivo, resultante da aplicação de conhecimentos científicos a tecnologias, adquiriu, em virtude da sua evolução, uma autonomia progressiva em 
relação à própria vontade humana, pois passou a ser realizado pela máquina e em função da máquina, que substituiu a mão do homem e 0 arado como instrumento de trabalho e produção de riquezas. (BARRETTO , 2005, p.664)

Com o desenvolvimento tecnológico, a relação entre técnica e ciência se incrementou. Atualmente, não é apenas a técnica que depende da ciência. 0 progresso da ciência também passou a depender da técnica. Da mesma forma que a ciência cria novas técnicas, a técnica cria novos objetos científicos. Esta interação entre ciência e técnica é a marca diferenciadora da tecnologia moderna. Assim, o desenvolvimento da tecnologia determinou todas as dimensões da atividade humana, implicando a necessidade de uma reflexão da forma da Sociedade, descrita a partir da tecnociência.

A tecnociência provocou transformações na cultura em que se desenvolvia o agir humano. A técnica moderna possibilitou o acesso humano a novos objetos de poder, ampliando o âmbito daquilo que o poder moderno poderia alcançar ou aquilo que o poder poderia produzir. Antes da tecnologia, toda interferência humana na natureza resultava em um "produto cultural". Por exemplo, a extração de madeira para se construir a casa, ou a cidade construída pelo homem. Entretanto, com a tecnologia, o ser humano passou a ter a capacidade de gerar produtos da natureza, que já não são "produtos da cultura", mas da natureza como tal. Isto é, o homem cria a natureza.

Atualmente, o homem não só se submete às leis da natureza para conhecê-la e dominá-la (como preconizava Bacon), mas também transforma estas leis. 0 homem alcançou a capacidade de alterar as próprias leis da evolução, podendo provocar conseqüências imprevisíveis. 0 homem passou a aderir ao imperativo da técnica, guiado pelo sentimento de que "tudo o que se pode fazer se deve fazer". A técnica deixou de ser um "meio", para se tornar um "fim", capaz de subordinar a si todas as exigências humanas. Com isso, o homem deixa de ser sujeito da técnica, para se tornar seu objeto.

A técnica deixou de ser um meio de satisfação das necessidades humanas, transformando-se em um fim que escapa do controle do ser humano. A tecnologia passa a ser um meio para que o homem supere os seus limites humanos, pondo à prova sua própria natureza corpórea. Exemplos dessas possibilidades são as manipulações genéticas, cujos efeitos são imprevisíveis e não se restringem a um indivíduo ou a um grupo determinado, 
mas produz efeitos para toda a existência no planeta, determinando o futuro das próximas gerações.

Como diz Paolo Becchi, por ter estendido o seu poder dessa forma, o ser humano,

[...] han alterado las relaciones con la naturaleza hasta el punto que hemos llegado, de poner en peligro su propia sobrevivencia sobre el planeta. Los hombre han pagado al crecentamento de su poder tecnológico no sólo con el extrañamiento de aquello sobre lo cual lo ejercitan, sino también con la destrucción de aquello que ha aprendido a dominar. (BECCHI , 2002, p. 118)

0 mundo criado pela tecnociência e seus novos objetos de poder colocam em perigo a própria conservação da humanidade e dos seres vivos, expondo-os a vários riscos, como a autodestruição (nuclear), a degradação irreversível do ambiente (como é o caso do aquecimento global), as mutações genéticas sem possibilidade de controle que alteram a natureza humana e extra-humana.

Assim, a tecnologia na sociedade tecnocientífica passa a constituir uma ação que não tem como ser imputada a um determinado sujeito. Na sociedade tecnocientífica há um obrar coletivo, cuja responsabilidade pessoal é, muitas vezes, impossível de ser determinada.

Esta ação produz efeitos globais, com uma relação de causalidade indemonstrável diante da complexidade de fatores que incrementam as suas consequências ao longo do tempo. A impossibilidade de se identificar 0 autor do ato que produziu 0 efeito torna a responsabilidade pessoal como a conhecemos inadequada para o controle desta nova forma do agir humano.

Em virtude do seu prolongamento no tempo, a ação humana passa a produzir efeitos imprevisíveis, não sendo possível determinar se as conseqüências da ação serão nocivas ou benéficas. 0 "bom" e o "mal" da ação não podem ser definidos no contexto imediato da ação. A ambivalência, a imprevisibilidade, a impossibilidade de determinação do nexo de causalidade entre ação e o efeito prolongado colocam a ideia de risco no centro da sociedade tecnocientífica.

\section{Ambivalência e Crise Semântica}


A ideia da existência de uma ordem imutável subjacente à realidade estava no centro do pensamento ocidental, mantendo-se sem grandes variações até o surgimento dos primeiros ensaios da filosofia da consciência. Naquele período, entendia-se que as coisas possuíam uma ordem natural, à qual todos os homens se conformavam. A natureza das coisas era compreendida como algo que sempre existiria do mesmo modo. Havia, portanto, uma imagem do mundo que era determinada de forma necessitária, onde as possibilidades para o engendramento da realidade já estavam previamente determinadas.

Nesta compreensão de mundo, as coisas possuíam uma essência imutável. 0 conhecimento do homem era produto do conhecimento da essência. Assim, implicava-se na necessária conformação do homem ao objeto (à natureza das coisas). Dessa forma, o homem não precisava compreender 0 mundo e se autocompreender em uma existencialidade. Afinal, o mundo era compreendido como algo dado ao ser humano.

A implicação desta forma de compreensão é que o homem não precisava se integrar no tempo como um todo. Isto é, o homem não reconhecia o passado como algo que o sustentava no mundo e o futuro como uma projeção de possibilidades para o seu modo de ser. 0 futuro era compreendido como algo necessário, e não como uma contingência. 0 tempo era pensado apenas como uma sucessão de "agoras", havendo uma predominância em relação ao presente. Havia uma simetria entre passado e futuro.

Na modernidade, o homem passa a constituir o mundo a partir de sua vontade. $A$ modernidade deixa de reconhecer uma ordem natural para as coisas que determinam o mundo do homem. 0 mundo passa a ser constituído a partir de um ato de vontade. A vontade do homem é produto de uma deliberação sobre a escolha de uma das possibilidades existentes para a produção deste mundo. Com isto, o homem passa a nomear e classificar o mundo. 0 ato de classificar e nomear significa separar, segregar, considerando o mundo como um conjunto de entidades discretas e distintas.

Ao classificar, é construída uma estrutura para o mundo, que possibilita a sua manipulação. Assim, esta estrutura tem o objetivo de fundar uma ordem, de bases sólidas, que ofereça as condições necessárias para que o homem possa habitar no mundo. Dessa forma, busca-se um controle do acaso. 0 mundo ordeiro é um mundo no qual sabemos como proceder, é um mundo onde o cálculo das probabilidades de um evento pode nos dar 
parâmetros para sabermos como devemos agir. Isso torna possível nos basearmos no sucesso do passado para que tenhamos um guia para o futuro (BAUMANN, 1999, p.12).

Entretanto, o que a modernidade não reconhece num primeiro momento é que todo ato de categorização produz um efeito ambivalente. Assim como temos várias possibilidades de mundo para deliberarmos sobre a escolha de uma delas e construirmos uma estrutura, a partir desta estrutura - constituidora de um mundo ordenado pelo homem - também existem várias possibilidades.

Isto torna os parâmetros da ética clássica insuficientes para fazermos um julgamento moral acerca da ação humana na sociedade tecnocientífica. Nesta sociedade, o homem desenvolveu a possibilidade de manipular a natureza, podendo modificar as leis que a engendram. A intervenção técnica na natureza passa a produzir efeitos globais e direcionados a um futuro longínquo. Entretanto, por não podermos prever estes efeitos, nem lhes atribuir juízos morais como correto ou errado, benéfico ou nocivo, a ação humana sobre a natureza torna vulnerável toda existência na terra.

Nesse sentido, a tentativa de controle dos efeitos futuros produzidos pela ação se torna ineficaz em decorrência da ambivalência. Toda tentativa de construção de ordem implica em mais desordem, em um nível maior de imprevisibilidade. Portanto, a ambivalência passa a estar intrínseca a toda ação. A partir disso, o homem passa a conceber o futuro como contingente.

A ambivalência dos efeitos da ação e a contingência são acentuadas pelo desenvolvimento tecnocientífico. O futuro passa a ser determinado pelos resultados e possibilidades teconcientíficas. Entretanto, estes resultados e possibilidades são ambivalentes por não podermos perceb ê-los a longo prazo como "bons" ou "maus".

Como discorremos no ponto anterior do presente texto, a potencialização da técnica no domínio científico, por influência dos postulados cientificistas modernos, leva a sociedade a um estágio de transição. A própria técnica acaba gerando uma sensação de desconforto pela falibilidade das premissas de seu conhecimento, isto é, as conseqüências da atividade científica, na utilização da técnica escapam a racionalização do procedimento moderno e passamos a ter que lidar com a contingência e o risco. 
O objeto a ser conhecido pela ciência moderna não coube nas suas premissas epistemológicas. Com isso, começou uma derrocada do projeto racionalista de descrição do mundo e do questionamento do sujeito cognoscente autodeterminado.

Como resultado do desenvolvimento destas ambivalências, o projeto moderno de controlabilidade e segurança epistemológica é arremessado em um vácuo de significação. 0 caminho escolhido pela postura científica dos modernos não os levou para o conforto da objetividade do conhecimento construído pelo sujeito que se autodetermina. O "sujeito conhecedor" não quer conhecer o que lhe apareceu, o seu novo objeto epistemológico não se curva às suas premissas epistêmicas, isto é, conhecer o risco não significou controlá-lo.

A modernidade começa a não se reconhecer mais no espelho. 0 grande navio da Razão tem dificuldades de flutuar após ganhar furos nietzschianos, freudianos e marxistas. Logo, os "marinheiros da racionalidade" passam de tripulantes enjoados a possíveis náufragos. Se nos permitirmos a manutenção desta metáfora, a pós-modernidade, nesse caso, é a bóia que sustenta os náufragos da razão moderna, sem poder saber exatamente para onde os leva.

Contrárias ou favoráveis ao rótulo da pós-modernidade, as teorias hodiernas da sociedade se duelam diante dos mais variados temas. A falta ou impossibilidade de uma descrição unitária do mundo, a ausência de uma razão vinculante, que ofereça uma referência norteadora para formação de nossos juízos, que ajude a enterrar nossas verdades e a reconstruir nossas perguntas. Enfim, impõe-se uma desconfortável crise semântica da modernidade.

Com uma complexidade e sofisticação coerentes com a realidade social, Niklas Luhmann observa a modernidade através de uma distinção entre estrutura social e semântica. A escolha por tal distinção se justifica pela assumida postura reflexiva de sua teoria. Logo, nada mais profícuo do que eleger, para a análise da modernidade, uma distinção que contenha a si mesma, ou seja, a distinção entre estrutura social e semântica é, ela mesma, uma distinção semântica. Segundo ele,

Este punto de partida contiene ya em su núcleo toda la teoría de la modernidad. Porque el análisis no empienza con el reconocimiento de acerditadas leys naturales, ni tampoco con princpios racionales e con hechos ya estabelecidos 0 indiscutibles. Empienza con una paradoja que habrá que resolver de uno o otro modo si si quiere reducir una carga informativa infinita a una finita. Con ello el 


\section{Modernidade e crise semântica: obstáculos epistemológicos à formação da prova do direito}

ambiental

analisis reclama para si las características de su objeto: modernidad (LUHMANN, 1997, p. 13-14).

O desenvolvimento da teoria luhmanniana, por si só, já exigiria um artigo a parte. Contudo, nos limitamos no presente trabalho a mencionar a crítica apontada pelo sociólogo alemão, no que tange a descrição da modernidade. Luhmann demonstra, com a observação supracitada, a necessidade de uma tematização da sociedade moderna em um nível semântico. Na busca por caracterizações potencialmente descritivas, o período moderno exemplifica-se como passagem de nítida dominância e destaque a razão, na construção da subjetividade e com a conseqüente valoração do sujeito do conhecimento. Ambos anteriormente apresentados.

Contudo, com uma lente luhmanniana observamos a insuficiência deste esquema teórico, atribuída pela descontextualização de sua operatividade. Ele não consegue observar a complexidade e a contingência, produtoras de risco na atual sociedade. Critica-se também as abordagens essencialmente histórico-conceituais, como a distinção antigüidade/idade média, que nada mais demonstra que uma escamoteada distinção de elogios e reprovações (LUHM ANN, 1997, p. 14-16).

O que concluímos, então, é a desorganização do sentido presente em nosso tempo. 0 discurso da pós-modernidade faz com que nos deparamos com a ameaça e a desconfiança nas formas de autodescrição da sociedade, construídas a partir de tentativas de metarelatos. Enfim, nas palavras de Luhmann $(1997$, p.9) "la proclamación de la posmodernidad tuvo al menos un mérito. Dio a conocer que la sociedad moderna había perdido la confianza en lo correcto de sus descripciones de sí misma".

\section{Ambivalência e complexidade na teoria probatória ambiental: da solidez à liquidez da prova}

As incursões pela teoria social moderna e "pós-moderna" se justificam para o operador do direito diante da emergência de uma radical trandisciplinaridade na esfera jurídico-ambiental.

A vida no foro, até então seara exclusiva da tradição praxista jurídica, se vê forçada a compartilhar seus domínios de produção de conhecimento com biólogos, geólogos, químicos, engenheiros, gestores ambientais, entre outros. Logo, para evitarmos que esta 
realidade se transforme em uma Torre de Babel, onde nossa dificuldade comunicativa comprometa nossa própria subsistência, a harmonização de nossos pressupostos teóricos e práticos se faz imperativa.

As fontes da teoria jurídica dominante derivam de um contexto específico gerado pelo ideal racionalista do período moderno (ROCHA, 2008, p. 1035). A compreensão dos institutos jurídicos atuais - inclusive a prova jurídica - depende de um processo de historicidade que revela o domínio moderno escamoteado em suas raízes fundantes. Descrevemos o paradigma moderno com o objetivo de demonstrar que este oferece 0 suporte à ideologia do direito e, por conseqüência, do processo e da teoria probatória.

A pertinência de tal proposta se comprova pela simples observação da raiz conceitual da prova. Na análise etimológica, segundo Moacyr Amaral dos Santos, prova,

[...] vem do latim - probatio - prova, ensaio, verificação, inspeção, exame, argumento, razão, aprovação, confirmação, e se deriva do verbo - probare (probo, as, are) - provar, ensaiar, verificar, examinar, reconhecer por experiência, aprovar, estar satisfeito de alguma coisa, persuadir alguém de alguma coisa, demonstrar (SANTOS, 1970, p.11).

Ora, qualquer semelhança com a postura empírico-racionalista, apresentada na primeira parte deste trabalho, não é mera coincidência. Fica nítida a concepção de prova como um amálgama entre os dois referencias teóricos acima sintetizados. A teoria clássica processual almeja desenvolver-se sobre uma base fática, direcionando a decisão jurídica para uma espécie de "sombra da verdade", que acarretaria uma sensação de segurança para as partes.

Assim, identificamos na teoria do direito probatório, um importante nicho de reflexão, não apenas das características do instituto da prova, mas também da própria autonomia/unidade da reconstrução jurídica da realidade. Neste tema, o operador do Direito se vê estimulado a transcender o Direito para produzir Direito.

A teoria probatória no Direito se vê ligada, de certa forma, a uma pretensão de gerenciamento da realidade que tem o fito de se relacionar com a verdade. Ela se constitui como um instrumento de captação dos fatos para o Direito, isto é, a prova seria uma estrutura (in)capaz de harmonizar verdade e validade. Em outras palavras, podemos 
começar a identificar a prova na esfera jurídica a partir da idéia de uma demonstração válida de fatos aptos a fundamentar/motivar a aplicação do Direito.

Entrementes, a conexão do Direito com conceitos como, verdade, certeza, realidade, para a doutrina mediada pela prova, necessita de uma constante especificação/evolução teórica. Nesse sentido, os problemas advindos da esfera ambiental funcionam como catalisadores dessas alterações. A constituição de juízos afirmativos sobre a existência de danos ambientais, a reconstrução de nexos causais responsivos, a oneração probatória, põem em xeque a capacidade do direito em abarcá-los sob um conceito de prova.

A irritação da doutrina com relação à complexidade destes problemas é manifesta. A dificuldade do tratamento dogmático destas questões pode ser verificada nas posturas doutrinárias que se conservam no paradigma racionalista, sem levar em consideração a especificidade constitutiva dos problemas ambientais. Como retrata a temerária afirmação de Leonardo Greco:

\begin{abstract}
Boa parte da doutrina especializada parece sobrepor, em matéria de fatos e de provas, a tutela da posição subjetiva da parte que alega postular em benefício do meio ambiente à de qualquer outro litigante, como se a proeminência desse bem jurídico impusesse um método de busca da verdade e de acertamento dos fatos privilegiado, em relação ao de que é titular qualquer outro postulante, com o sacrifício da noção moderna de processo justo à de um direito processual a serviço de um autor, o que não só compromete a isonomia, mas também a própria neutralidade e impessoalidade da jurisdição (GRECO, 2005, p. 41, grifo nosso)
\end{abstract}

Compartilhamos da preocupação de Greco no que diz respeito à possibilidade de que nos processos que tenham como objeto a litigiosidade emergente do meio ambiente ocorra uma corrupção da isonomia processual, favorecendo toda e qualquer pretensão supostamente ligada à proteção do meio ambiente. Contudo, discordamos da negativa inferida por ele no que tange ao método de conhecimento dos problemas ambientais. A especificidade da tutela ambiental impõe um aprimoramento da epistemologia probatória clássica (CARVALHO, 2008, p. 56), que axiomatiza o causalismo na formação da prova.

Contudo, como orientaremos nossos "marinheiros racionalistas" desprovidos do barco da razão moderna e que estão a flutuar nas bóias da pós-modernidade? Quais os indícios que podemos seguir para enfrentarmos esta carência de significação? Sem a pretensão de indicarmos a solução acabada ou uma resposta confortante para nossa 
angústia atual, podemos encontrar na metáfora baumanniana que, ao polarizar a liquidez e a solidez para descrever a modernidade, nos chamou atenção da diferença entre estes dois estados (líquido e sólido) consistente na diferença de suas "ligas" constitutivas (BAUM ANN, 2001, p. 16).

\section{Conclusão}

Ficou demonstrado que a "liga" da solidez do período moderno constituía-se pela razão de um sujeito cognoscente, produtor de um projeto de controlabilidade epistemológica. Com a falência do projeto moderno, as bases de formação do conhecimento e da ciência foram transgredidas pela complexidade emergente das relações sociais e das novas descobertas científicas. Portanto, com o desmantelamento da "liga" da modernidade caímos, inexoravelmente, em um vazio semântico de nossa estrutura.

A litigiosidade ambiental é fruto de uma sociedade diferente daquela em que 0 processo moderno teve a sua prova pensada e constituída. 0 processo ambiental deve possibilitar novas estruturas epistemológicas com vistas à assimilação da complexidade e contingência englobantes da descrição dos problemas ambientais.

O desafio que se impõe é pensar e construir uma nova liga, que dê conta da fluidez, ambivalência e contingencialidade do perío do atual. A condição para observarmos o direito e sua teoria probatória, principalmente nas demandas ambientais, depende do avanço ou da superação deste desafio.

\section{Referências}

AM ARAL SANTOS, Moacyr. Prova Judiciária no Cível e Comercial. 4. Ed. São Paulo: Max Limonad, 1970. v. 1.

BARRETTO, Vicente de Paulo. O vaso de pandora da biotecnologia: impasses éticos e jurídicos. In: TÔRRES, Heleno Taveira. Direito e Poder: nas instituições e nos valores do público e do privado contemporâneos. Barueri: Manole, 2005.

BAUM ANN, Zygmunt. M odernidade e ambivalência. Rio de Janeiro: Jorge Zahar, 1999. 
. Modernidade líquida. Rio de Janeiro: Jorge Zahar, 2001.

BECCHI, Paolo. La Ética en la era de la técnica, elementos para una crítica a kart-Otto Apel y Hans Jonas, Doxa. Filosofia del Derecho, n. 25, p. 117-137, 2002.

CARVALHO, Délton W. de. Dano Ambiental Futuro: a responsabilidade civil pelo risco ambiental. Rio e Janeiro: Editora Forense Universitária, 2008.

DILTHEY, Wilhelm. Introducción a las ciencias del espíritu. Buenos Aires : Espasa-Calpe, 1948. FERRARTER M ORA, José. Diccionário de Filosofia. Tomos I e ll. Buenos Aires: Editorial Sudamerica, 1971.

GRECO, Leonardo. As provas no processo ambiental. Revista de Processo, v. 30, n. 128, out. 2005.

HOTTOIS, Gilbert. El paradigma bioético: una ética para la tecnociencia. Barcelona: Anthropos Editorial, 1999.

HÜBNER, Kurt. Técnica. In: KRINGS, Hermann; BAUM GARTNER, H. M.; WILD, C. Conceptos fundamentales de filosofia. Barcelona: Herder, 1979.

LUHM ANN, Niklas. Observaciones de la modernidad: racionalidad y contingencia en la sociedad moderna. M éxico: Paidós, 1997.

ROCHA, Leonel S. Da epistemologia jurídica normativista ao construtivismo sistêmico. Stvdia Ivridica 90. Boletim da Faculdade de Direito: Coimbra Editora, 2008. 